\title{
OPTIMIZATION OF 3 AXIS ANTENNA SYSTEM
}

\author{
Nitin Kabadi Srinivasa ${ }^{1}$, C.Narasimhe Gowda ${ }^{2}$ \\ ${ }^{1}$ Post graduate student, Department of Mechanical Engineering, Dayananda Sagar College of Engineering, \\ Bangalore, India \\ ${ }^{2}$ Asst. Professor, Department of Mechanical Engineering, Dayananda Sagar College of Engineering, Bangalore, India
}

\begin{abstract}
Antenna structure is a supporting system which takes the load of different components it houses and transfers the load to the ground. Antenna structure is subjected to various loads such as self-weight, wind loads and even dynamic loads due to the presence of rotating components in the structure. The design and safety plays an important role because it has to efficiently receive and transfer the radio signals to the target.

All physical system vibrates. The frequency at which the vibration naturally occur is called the natural frequency. The deformed shape of the structure at a specific natural frequency of vibration is termed as its normal mode of vibration. Each mode shapes is associated with a specific natural frequency. If the exciting frequency coincides with the natural frequency of the structure, resonance occurs.
\end{abstract}

So the main objective of this work is to find the natural frequency of the structure and to keep it away from the exciting frequency by optimization. Optimization is carried by varying stiffness and mass of the structure.

Keywords -3 axis Antenna; Natural Frequency; Mode Shapes; Optimization; - ***

\section{INTRODUCTION}

Antenna is a structure connecting the receiver/transmitter to free space. The prime function of the antenna is to provide an efficient link between the ground station and the satellite. The antenna also provides the spatial orientation of the target by angular information. Antenna supporting structure is the one which supports the antenna during its course of action. The structure should meet certain mechanical specifications to withstand various loads and other factors which influence the functioning of antenna system. The structure has subassemblies and components. It has to provide rigidness, such that the radio waves transmitted and received are focused accurately at the focal point because accuracy in turn determines the overall quality of the signals.

This antenna supporting structure contains 10 sub components. Optimization of components is carried out based on Natural Frequency constraint.

\section{OPTIMIZATION}

The mechanical design of the Antenna structure is generally driven by the constraints on the structural natural frequency.

When any object, vibrates at the same natural frequency of the second object, it forces that second object into vibrational motion. This is called resonance. The result of resonance is always a large vibration. Regardless of vibrating system if resonance occurs, a large vibration results.
Structural design optimization is a specialized utilization of numerical design optimization that has been adapted to cater especially for structural design problems. Some of the most common structural optimization applications include the mass minimization of a structure, Maximization of the stiffness, structure failure prevention and data matching. This report focuses on the specific application FEA methodology in the analysis of a Three axis Antenna system. The data of interest is the dynamic characteristics, specially the modal frequencies and mode shapes, of an antenna structure.

\section{PROBLEM DESCRIPTION}

The geometric model is created using CATIA V5R17 from the design specifications obtained. The model consists of several components. Each component are modeled and assembled to form a Global model.

The following are the list of the individual components of the Antenna structure.

- Azimuth Base Housing : It is the base which takes the entire load of the structure, and it is rigidly fastened to the ground. It also houses motors to drive the system.

- Slew Ring Bearing : A cylindrical bearing which having high stiffness, which comprises of inner and outer race to transfer rotary motion between various components.

- Horizontal Elevation Housing : It is a horizontal component supported by bearing upon which Vertical Yoke Arm Front and Rear is rigidly mounted.

- Vertical Yoke Arm Front and Vertical Yoke Arm Rear: These are the Vertical structures which hold Elevation Housing through bearings. 
- Elevation Housing : It is a component which houses motors to drive and hence support Top Elevation Yoke Arms vertically through bearings.

- Top Elevation Yoke Arm : These are the vertical structures connected to the Intermediate Frame and the counter weights are attached to this component.

- Counter Weights : It provides balance to the structure while the reflector rotates and helps to maintain the center of gravity at the desired position.

- Intermediate Frame : It is a rectangular frame upon which the Reflector Backing Structure is mounted.

- Reflector Backing Structure : It is the base upon which the Reflector is mounted.

- Reflector : It is a parabolic dish which receives the radio waves and directs it to the feed and also helps in transmitting the signal from the Antenna.

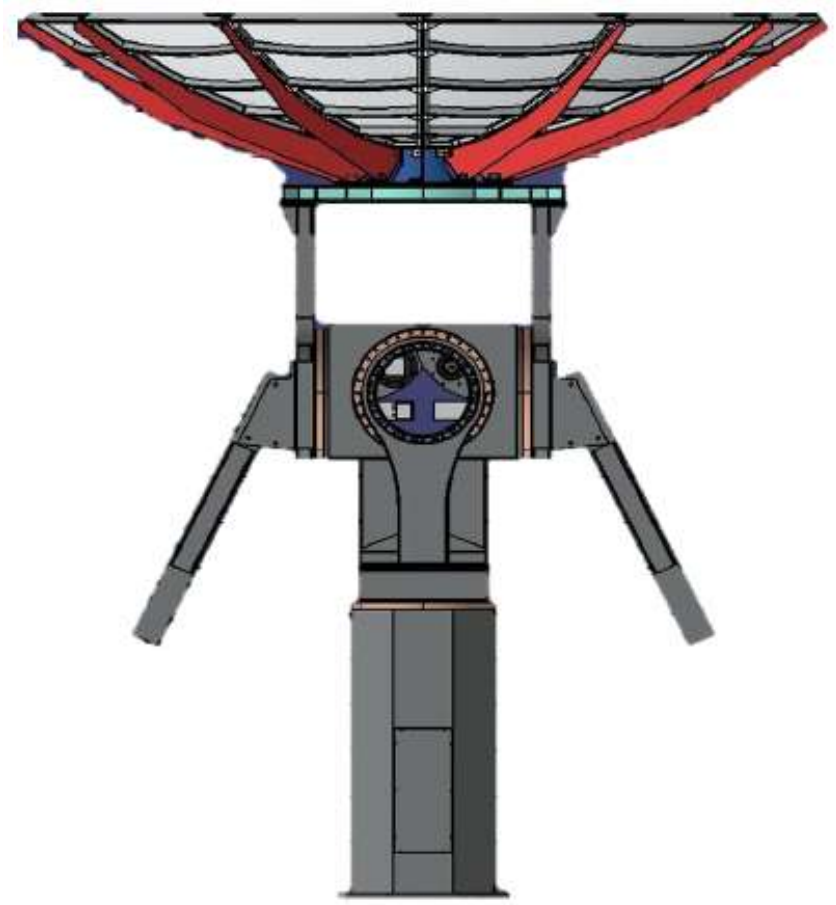

Fig: 1 Three axis Antenna System

The Antenna supporting structure consists of 6 motors to steer the antenna to desired orientations. The natural frequency of these motors is in the range of 1-2 Hz.

The natural frequency of the antenna structure must be away from this resonant frequency.

\section{FINITE ELEMENT MODELLING}

The Finite Element Model is created using Altair Hypermesh V11. Each component is meshed individually and then assembled with necessary Boundary conditions for further analysis.

Since the antenna structure being analyzed is hollow in nature with minimal thickness, the most appropriate method to analyze the structure is using 2D SHELL elements.
Mid-surface provides a platform for the user to mesh the component with 2DSHELL elements and assigning the required thickness, hence this approach is employed in our work.

The element types used for meshing are SHELL63, SOLID185, BEAM188, COMBIN14, CERIG, MASS21.

The main steps followed in FEM are

- Importing Geometrical model to Hypermesh

- Extraction of midsurface and geometry cleanup.

- Meshing using Ruled, Automesh and Spline technique.

\subsection{Quality Checks}

The element quality directly influences the analysis results. Hence, necessary quality checks were carried out and ensured that all the elements met the required quality standards.

Table : 1 Quality Parameters

\begin{tabular}{|c|c|c|c|c|}
\hline S1 & $\begin{array}{c}\text { Quality } \\
\text { parameter }\end{array}$ & $\begin{array}{c}\text { Ideal } \\
\text { value }\end{array}$ & $\begin{array}{c}\text { Acceptable } \\
\text { value }\end{array}$ & $\begin{array}{c}\text { Achieved } \\
\text { value }\end{array}$ \\
\hline 1 & Warpage & $0^{0}$ & $<10^{\circ}$ & .0554 \\
\hline 2 & Skew & $0^{0}$ & $<45^{0}$ & 42.96 \\
\hline 3 & Jacobian & 1 & $>.6$ & .6 \\
\hline
\end{tabular}

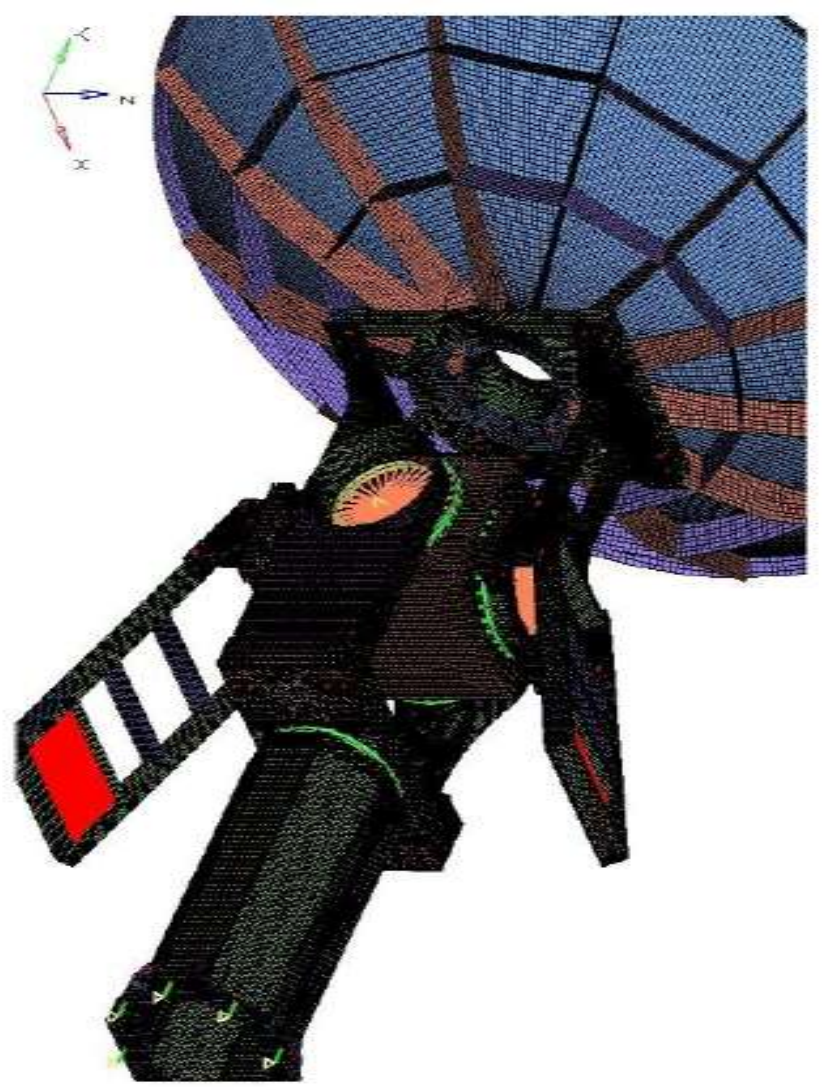

Fig: 2 FE Model of Antenna Structure 
The material properties are:

- Young's Modulus(E)=2.1e5 N/mm^2

- Poisson's ratio $($ Nuxy $)=0.3$

- $\quad$ Density(DENS)=7.85e-9 ton $/ \mathrm{mm}^{\wedge} 3$

The boundary condition is:

Azimuth Base Housing is fixed to the ground using bolts, All the six degrees of freedoms are constrained such that it cannot move in any plane or rotate in an any axis freely.

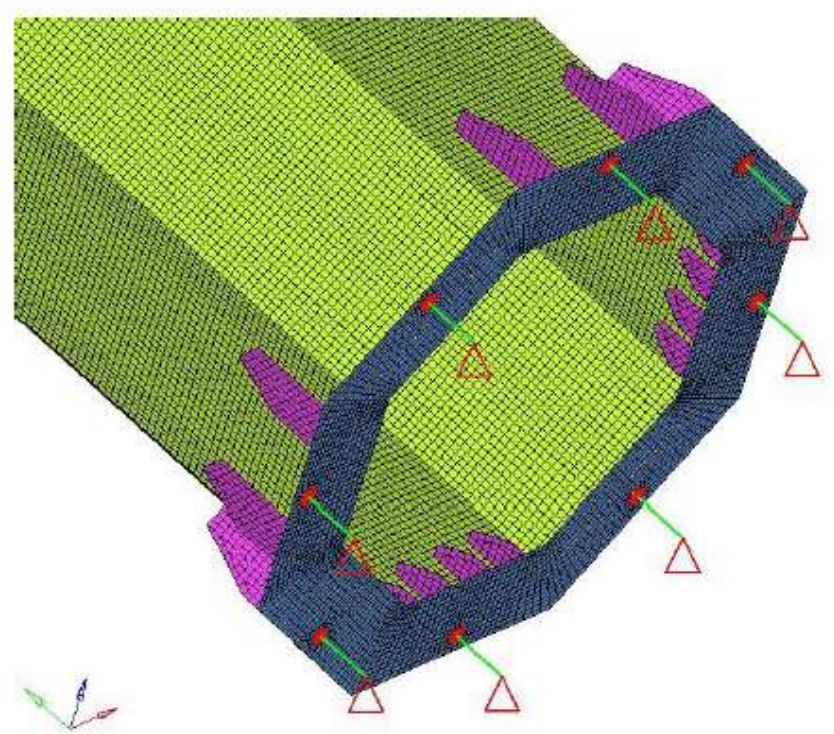

Fig : 3 All 6 dof constrained at Azimuth base

\section{RESULTS AND DISCUSSIONS}

The Global FE model of Antenna structure was analyzed in Ansys for natural frequency and mode shapes.

The results from the modal analysis are given in the table and the figures that follow:

Table: 2 First five natural frequencies of antenna structure.

\begin{tabular}{|c|c|}
\hline Mode number & Natural frequency(Hz) \\
\hline 1 & 4.71 \\
\hline 2 & 6.19 \\
\hline 3 & 7.71 \\
\hline 4 & 8.92 \\
\hline 5 & 9.07 \\
\hline
\end{tabular}

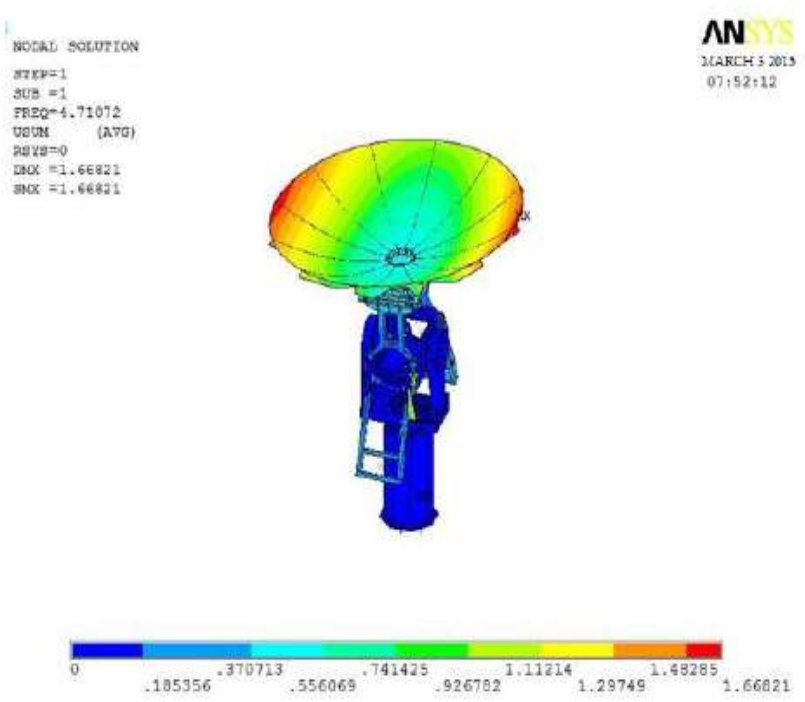

Fig: 4 First mode with natural frequency $4.71 \mathrm{~Hz}$

\section{OPTIMIZATION PROCESS}

As the motor bandwidth is in the range of $1 \mathrm{~Hz}$ to $2 \mathrm{~Hz}$, there is a need to increase the natural frequency of the structure in order to ensure safe working of the system.

Natural frequency of the system before optimizing was found to be $4.71 \mathrm{~Hz}$.

\subsection{Optimization through Thickness Variation}

The initial geometrical thickness of the components is assumed to be $100 \%$ thickness. The thickness of the components was varied in equal proportions and the corresponding overall natural frequency of the system was determined.

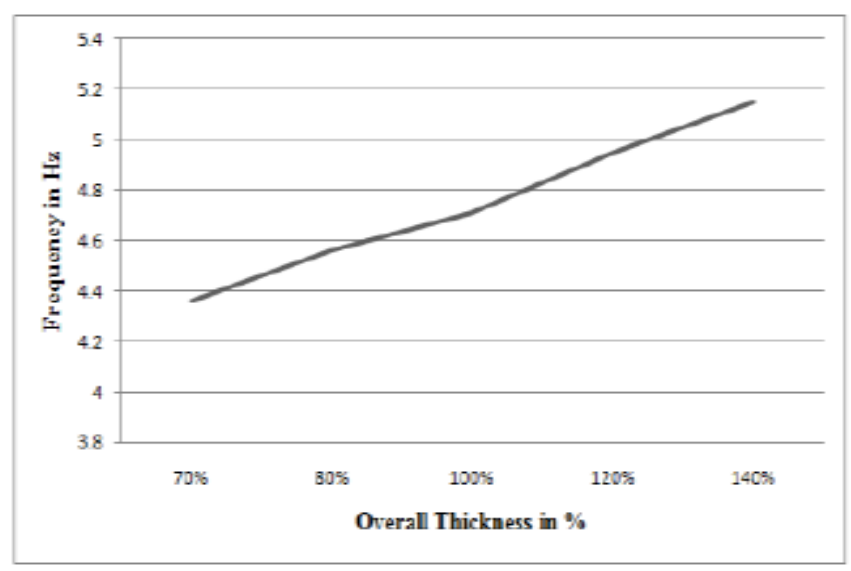

Fig: 5 Results of thickness variation

\subsection{Selective Optimization}

In this method components are made stiffer either by introducing stiffeners/ribs, or reducing the mass of a selected component, such that the natural frequency of the entire structure changes by a marginal value. 


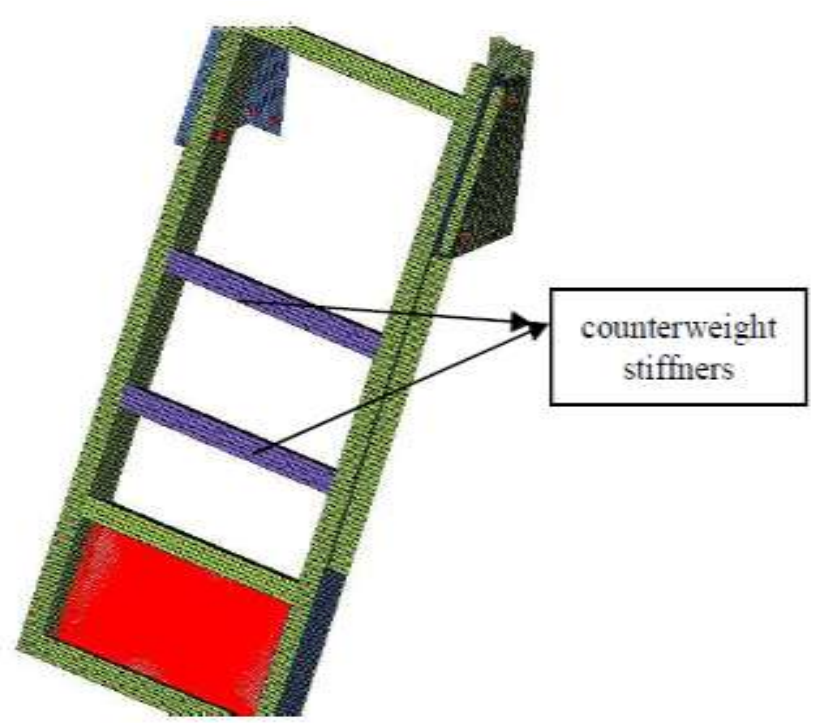

Fig: 6 Counterweight stiffners

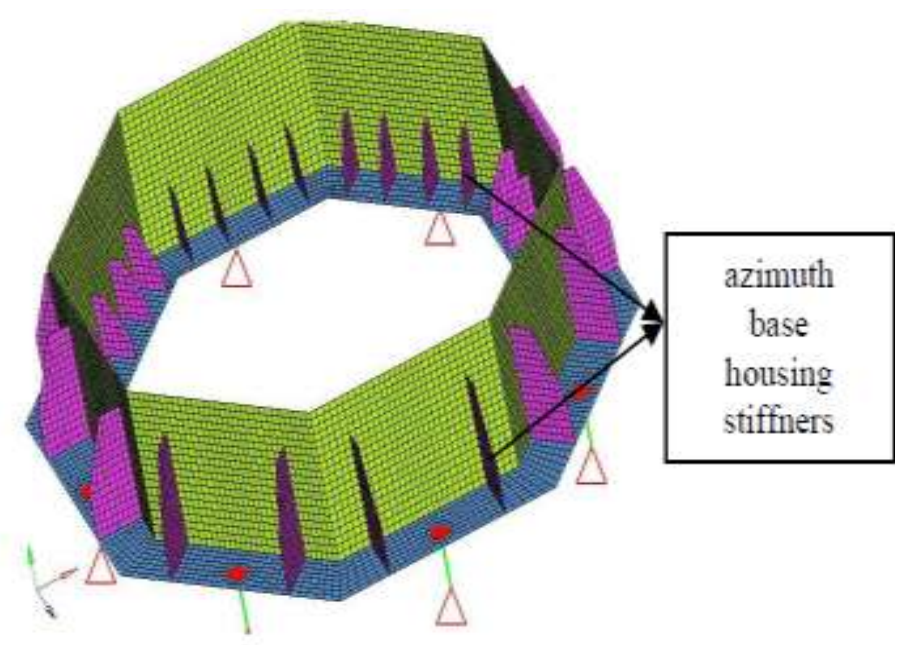

Fig: 7 Azimuth base housing stiffeners

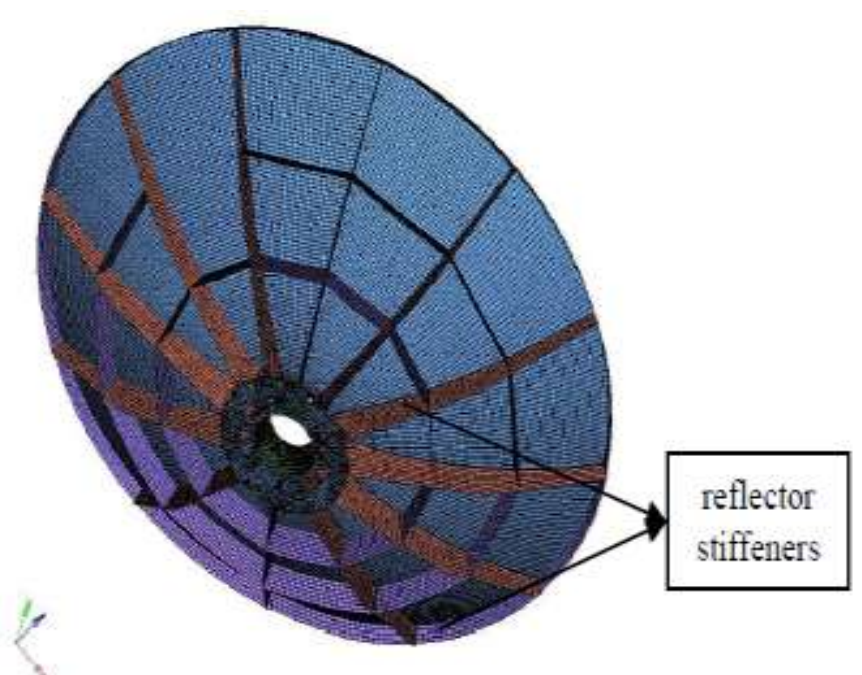

Fig: 8 Reflector Stiffeners

With these modifications, the natural frequency obtained is $6.28 \mathrm{~Hz}$.

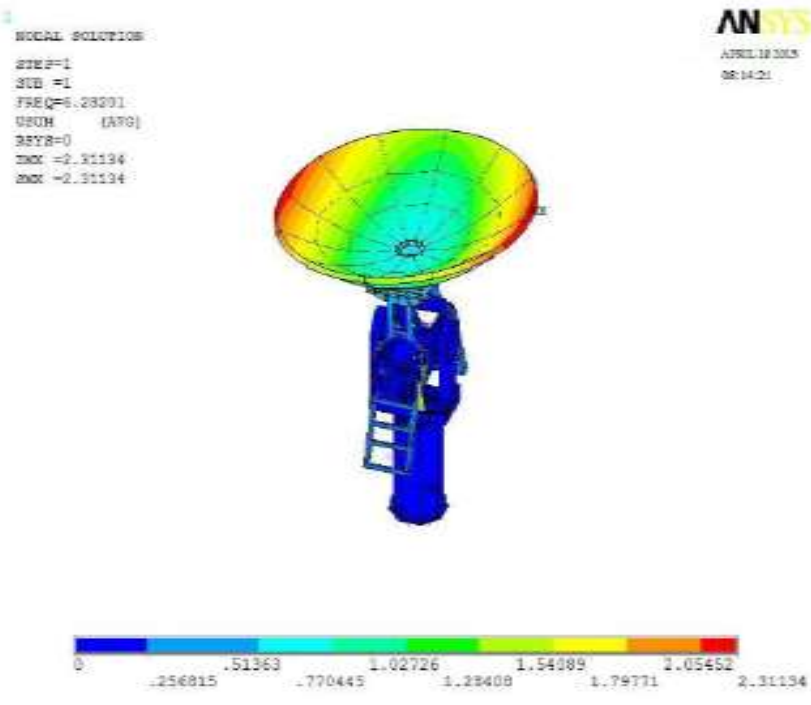

Fig: 9 Antenna structure with natural frequency $6.28 \mathrm{~Hz}$

Table: 3 Results of selective optimization

\begin{tabular}{|l|l|l|l|l|l|l|}
\hline \multicolumn{1}{c|}{} & iterations & 1 & 2 & 3 & 4 & 5 \\
\hline & $\begin{array}{l}\text { Reflector dish } \\
\text { stiffeners }\end{array}$ & 2 & 2 & 1.6 & 1.6 & 1.6 \\
\cline { 2 - 7 } & $\begin{array}{l}\text { Counter weight } \\
\text { stiffeners }\end{array}$ & 2 & 2 & 2 & 2 & 5 \\
\cline { 2 - 7 } & $\begin{array}{l}\text { Azimuth base } \\
\text { stiffeners }\end{array}$ & 8 & - & - & 5 & 5 \\
\cline { 2 - 7 } & $\begin{array}{l}\text { Azimuth base } \\
\text { ribs }\end{array}$ & 8 & 8 & 5 & 5 & 8 \\
\hline & $\begin{array}{l}\text { Natural } \\
\text { frequency(Hz) }\end{array}$ & 5.93 & 6.00 & 6.17 & 6.22 & 6.28 \\
\hline
\end{tabular}

\section{CONCLUSION AND FUTURE WORKS}

Initially the natural frequency of the structure was found to be $4.71 \mathrm{~Hz}$. Two methods were employed in the optimization,

- optimization through thickness variation: The maximum value of natural frequency that was obtained in this method was $5.16 \mathrm{~Hz}$.

- Selective optimization: The maximum value of natural frequency that was obtained in this method was 6.28 $\mathrm{Hz}$.

From the comparison it can be concluded that Selective optimization gives better result and hence it is a better method of the two.

Further optimization which is more sophisticated and accurate is being carried out using Ansys Workbench and optistruct.

\section{REFERENCES}

[1]. Brendon Ryan Potgieter, 2010, "Experimental Modal Analysis and Model Validation of Antenna Structures" 
[2]. Nitin S Gokhale, Sanjay S Deshpande, Sanjeev V Bedekar, Anand N Thite, 2008, "Practical Finite Element Analysis", First edition, Finite to Infinite.

[3]. SaeedMoaveni, 2011, "Finite Element Analysis-Theory and application with Ansys", Third edition, Pearson education Inc.

[4]. Tirupathi R Chandrupatla, Ashok D Belegundu, 2011, "Introduction to Finite Elements In Engineering", Third edition,Pearson education Inc.

[5]. Ansys help 